\title{
Associations Between Croatian Adolescents' Use of Sexually Explicit Material and Sexual Behavior: Does Parental Monitoring Play a Role?
}

Tomić, Ivan; Burić, Jakov; Štulhofer, Aleksandar

Source / Izvornik: Archives of Sexual Behavior, 2017, 47, 1881 - 1893

Journal article, Accepted version

Rad u časopisu, Završna verzija rukopisa prihvaćena za objavljivanje (postprint)

https://doi.org/10.1007/s10508-017-1097-z

Permanent link / Trajna poveznica: https://urn.nsk.hr/urn:nbn:hr:131:529736

Rights / Prava: In copyright/Zaštićeno autorskim pravom.

Download date / Datum preuzimanja: 2023-04-26

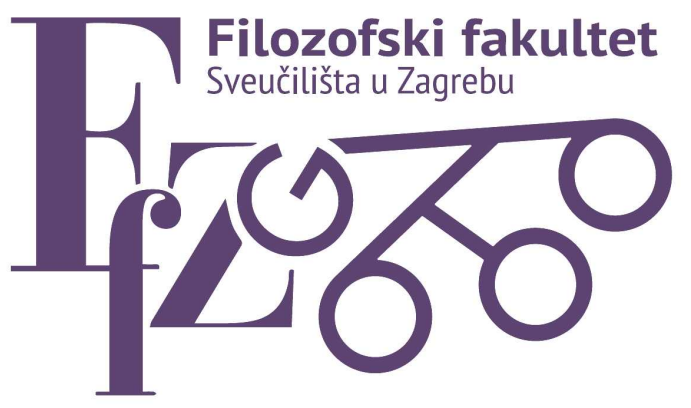

\section{Repository / Repozitorij:}

ODRAZ - open repository of the University of Zagreb Faculty of Humanities and Social Sciences
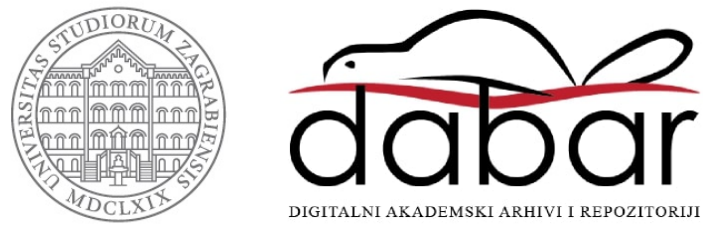
Associations between Adolescent Use of Sexually Explicit Material and Sexual Behavior:

Does Parental Monitoring Play a Role? 


\begin{abstract}
:
The use of sexually explicit material (SEM) has become a part of adolescent sexual socialization, at least in the Western world. Adolescent and young people's SEM use has been associated with risky sexual behaviors, which has recently resulted in policy debates about restricting access to SEM. Such development seems to suggest a crisis of the preventive role of parental oversight. Based on the Differential Susceptibility to Media Effects Model, this study assessed the role of parental monitoring in the context of adolescent vulnerability to SEMassociated risky or potentially adverse outcomes (sexual activity, sexual aggressiveness and sexting). Using an online sample of Croatian 16-year-olds $(N=1,265)$ and structural equation modeling approach, parental monitoring was found consistently and negatively related to the problematic behavioral outcomes, regardless of participants' gender. While SEM use was related to sexual experience and sexting, higher levels of parental monitoring were associated with less frequent SEM use and lower acceptance of sexual permissiveness. Despite parents' fears about losing the ability to monitor their adolescent children's lives in the Internet era, there is evidence that parental engagement remains an important protective factor.
\end{abstract}

Kewords: adolescents; sexually explicit material; parental monitoring; sexual experience; sexting; sexual aggressiveness 


\section{Associations between Adolescent Use of Sexually Explicit Material and Sexual Behavior: \\ Does Parental Monitoring Play a Role?}

\section{INTRODUCTION}

The prevalence of sexually explicit material (SEM) use among adolescents appears substantial. In a cross-sectional survey of 4,600 Dutch 15- to 25-year-olds, Hald, Kuyper, Adam, and de Wit (2013) reported that more than $88 \%$ of male and $44 \%$ of female participants had used SEM in the past 12 months. Comparable findings were reported in a population-based Swedish study, in which $95 \%$ of the surveyed male 16-year-olds used SEM (Mattebo, Tyden, HaggstromNordin, \& Nilsson, 2013). In an earlier study, the 2010 retrospective assessment of early SEM use in a national probability based sample of Croatian emerging adults, a substantial minority ( $40 \%$ of female and $39 \%$ of male participants) reported exposure to SEM before the age of 15 (Sinković, Štulhofer, \& Božić, 2013). About a third (34\%) of female and a majority (79.5\%) of male participants reported SEM use in the past 12 months. High prevalence of SEM use, particularly among male adolescents, has raised discussions about its adverse outcomes and prompted research into potential SEM-related health risks.

The ubiquity of online SEM has raised institutional concerns over the developmental consequences of child and adolescent SEM use (Carrol et al., 2008). In the U.K., for example, these concerns were recently documented in the Office of the Children's Commissioner's report (Horvath, Alys, \& Massey, 2013), which prompted new legislation intended to help parents and educators monitor young people's exposure to unwanted online content (Petley, 2015). Considering that parents often feel ill-equipped to understand and efficiently monitor their children's online activities (Clark, 2014) —including a growing exposure to SEM-are parents becoming helpless to prevent unwanted outcomes? Based on the Differential Susceptibility to 
Media Effects Model, in this study we explored the role of parental monitoring in the context of adolescent vulnerability to three SEM-associated risky or potentially adverse outcomes: sexual activity, sexual aggressiveness and sexting. Although a recent 2-wave study carried out among the Dutch teenagers reported that communication with parents about sexualized media failed to reduce the levels of sexual activity and sexual permissiveness (Nikken \& de Graf, 2013), little is known about the role of parents in adolescents' experiences with SEM and the associated behavioral and attitudinal outcomes.

\section{Buffering Role of Parental Involvement?}

Peers are not the sole source of social influence in adolescence. For example, Whitaker and Miller (2000) reported that the association between peers' sexual activity and the adolescent's sexual behavior was significantly moderated by discussing sexuality with one's parents. Adolescents who discussed sexual initiation with a parent were characterized by a later sexual debut and tended to have fewer sexual partners than their peers who reported no such conversations. Another study observed that female adolescents who had more sexually experienced friends and who experienced more peer pressure to be sexually active had a lower likelihood of becoming pregnant if their mothers had a stricter parenting style and applied better monitoring (East, Khoo, \& Reyes, 2006). Several longitudinal studies pointed to positive effects of the quality of parent-child relationship on adolescents' sexual debut timing, intentions to become sexually active, and sexual risk taking (de Graaf, van de Schoot, Woertman, Hawk, \& Meeus, 2012; Deptula, Henry, \& Schoeny, 2010; Van de Bongardt, de Graaf, Reitz, \& Deković, 2014).

Parental monitoring usually describes parental knowledge of the child's whereabouts, activities and company (Sieverding, Adler, Witt, \& Ellen, 2005; Wang, Stanton, Deveaux, \& Lunn, 2015), with the literature pointing to its importance for health sexual development 
(Borawski, Ievers-Landis, Lovegreen, \& Trapl, 2003). Wight, Williamson, and Henderson (2006) observed that young people with high parental monitoring at baseline reported fewer sexual experiences than their peers two years later. Among female participants, high parental monitoring was also related to more frequent condom and contraception use. In a longitudinal study carried out among 13- to 17-year-old adolescents in the Bahamas, initial levels of parental control had protective effects on sexual risk-taking 18 months later among both male and female adolescents (Wang et al., 2015). Parental monitoring can also buffer the effects of adolescent exposure to problematic media content, either directly, by restring access, or indirectly--by enabling an active and mediating parental engagement. For example, female adolescents who have spent less time discussing TV programs with their parents were twice as likely to have had sex compared to those who discussed the content more frequently (Peterson, Moore, \& Furstenberg, 1991).

\section{Pornography and Hastened Sexual Activity}

The suggestion that SEM use is becoming a part of young people's sexual socialization (Sun, Bridges, Johnson, \& Ezzell, 2016; Wright, 2011), at least in the Western world, has been repeatedly addressed in the context of sexual risk-taking. Although the evidence is not univocal (Luder et al., 2011; Peter \& Valkenburg, 2011; Sinković et al., 2013), adolescent and young people's SEM use has been associated with risky sexual behaviors, including intentions to become sexually active earlier than one's peers (Pardun, L'Engle, \& Brown, 2005) and earlier sexual debut (Collins et al., 2004). Watching sexually suggestive media has been positively related to young people's expectations about sex and sexual initiation (Brown \& L'Engle, 2009; Brown et al., 2006; Kraus \& Russell, 2008). Focusing on SEM, a recent two-wave panel study carried out among 12- to 16-year-old Belgians found that frequent users were more likely to initiate sex than non-users (Vandenbosch \& Eggermont, 2013). Importantly, the effect was stronger among younger participants - i.e., those of early, compared to late, pubertal status. 


\section{Pornography and Sexual Aggressiveness}

Historically, the possible contribution of SEM use to sexual aggression has been among the key social concerns about SEM (cf. Hald, Seaman, \& Linz, 2014). Although the issue has been extensively researched in adults (for an overview see Wright, Tokunaga, \& Kraus, 2015), studies focusing on SEM use and sexual aggressiveness among adolescents are rare (Peter \& Valkenburg, 2016). In a study among Italian adolescents, SEM exposure was associated with having forced someone to have sex (Bonino, Ciairano, Rabaglietti, \& Cattelino, 2006). Using a longitudinal design, Brown and L'Engle (2009) found that male adolescents' SEM use at baseline significantly predicted their reports of sexually harassing someone at wave two, two years later. In another longitudinal study carried out on a national sample of 10- to 15-year-old adolescents in the United States, the authors found that the use of material operationalized as violent SEM substantially increased the likelihood of sexually aggressive behavior over time (Ybarra, Mitchell, Hamburger, Diener-West, \& Leaf, 2011). No association was observed in the case of non-violent SEM use.

\section{Pornography and Sexting}

Although the practice of sexting — usually defined as sending online sexual messages, sexy photographs, or videos of oneself to someone (Temple et al., 2014) — has been found popular among young people (Klettke, Hallford, \& Mellor, 2014; Mitchell, Finkerhor, Jones, \& Wolak, 2012; Rice et al., 2012), there is a dearth of research on the possible link between SEM use and sexting. A suggestion that sexing, being a form of sexual experimentation, may be linked to SEM use (Owens, Behun, Manning, \& Reid, 2012), was explored in a sample of 15-21 yearold Belgian students (Van Ouytsel, Ponnet, \& Walrave, 2014). The authors reported a positive correlation between SEM, which was operationalized to include both 'softcore' and 'harcore' contents, and different sexting behaviors in both young men and women. The findings are 
compatible with the notion that sexualized media increase motivation for sexting (van Ouytsel, Walrave, \& Van Gool, 2014). This may be particularly relevant in the case of SEM, due to its particular subcultural effect - the so called porno-chic (McNair, 2008) - that seems to encourage highly sexualized self-presentations.

Although sexting is not a risky behavior in itself, it has been associated with earlier sexual initiation (Temple \& Choi, 2014), a higher number of sexual partners (Benotsch, Snipes, Martin, \& Bull, 2013; Dake, Price, Mazriaz, \& Ward, 2012), a higher risk of unprotected sex (Dake et al., 2012; Ferguson, 2011) and reporting a sexually transmitted infection (Benotsch et al., 2013).

Importantly, a considerable number of adolescents reported that they felt pressured into sexting by their peers (Walrave, Heirman, \& Hallam, 2014). As some young people pass along the received sexts to a wider audience (Boulat et al., 2013), leaked sexts can result in shaming and harassing of the person who created them (Ringrose, Gill, Livingstone, \& Harvey, 2012). In addition, when addressed to unintended individuals, sexting becomes a form of cyberbullying (Dake et al., 2012), which can have legal ramifications.

\section{Current Study}

The Differential Susceptibility to Media Effects Model (DSMM) is a recently proposed integrative theoretical conceptualization of roles and relationships among media and non-media constructs (Valkenburg \& Peter, 2013). The DSMM aims to provide a theoretical micro-level answer to the following questions: (1) what makes some individuals more vulnerable to media effects; (2) how does media influence actually work; and (3) how can media effects be counteracted? Building on the well-documented conditionality of media effects, Valkenburg and Peter distinguish among three types of (differential) susceptibility to media effects: dispositional (gender, personality characteristics and attitudes), developmental (adolescence as a particularly vulnerable period) and social susceptibility (family and peer environments, culture-specific 
norms and institutions). The DSMM also posits that media effects are indirect-i.e., that the link between exposure and effects is mediated by three "media response states" (cognitive, emotional and excitative; Valkenburg \& Peter, 2013).

Focusing on dispositional and social susceptibilities, this study tested a structural model that assessed the role of parental monitoring in adolescent vulnerability to SEM-associated risky or potentially adverse sexual outcomes. The model, presented in Figure 1, assessed the association between SEM use and three behavioral outcomes (earlier sexual debut, sexual aggressiveness and sexting), controlling for parental monitoring. A negative association between parents' involvement and risky outcomes, counterbalancing their positive relationship with SEM, was hypothesized. Furthermore, to explore if dispositional factors are related to the key relationship (SEM and risky outcomes), sexually permissive attitudes were also included in the model, with an expectation that adolescents' permissiveness may be influenced by sexualized media, particularly SEM, but also by family socialization.

Building on previous research (Peter \& Valkenburg, 2010; Baams et al., 2015), the model also included an important element of the cognitive response to SEM-perceived pornography realism or a degree to which users believe that SEM portrays common or everyday sexual interactions (Peter \& Valkenburg, 2016). More precisely, we examined if perceived realism mediated the association between SEM and the target behaviors (i.e. sexual initiation, sexting, and sexual aggressiveness), hypothesizing that higher levels of pornography realism represented a higher likelihood of the scripting (or socializing) effects of SEM (Sun et al., 2016; Wright \& Donnerstein, 2014).

To the best of our knowledge, this is the first study to explore the buffering role of parental monitoring in the context of adolescent SEM use. Our findings are intended to inform the field, especially the research focusing on potential harm associated with adolescent use of 
SEM, but also to provide insights relevant to parents and educators. At least in part, the rising concerns over the detrimental effects of sexualized media- online SEM in particular-seem to be fueled by parents' increasing difficulties with supervising their children's Internet experiences. School-based comprehensive sexuality education programs have only recently begun to incorporate media literacy content and modules designed to assist young people in dealing with often highly sexualized popular media (Scull, Malik, \& Kupersmidt, 2014).

\section{METHOD}

\section{Participants}

In April and May 2015, 2,655 $10^{\text {th }}$ grade students completed an online survey about the use of sexualized media. During data cleaning, 414 cases $(16 \%)$ were excluded — mostly because of a large percentage of skipped questions — resulting in the final sample of 2,241 adolescents. Female students comprised 58\% of the sample. Participants' mean age was 16.2 years $(S D=$ 0.50). The sample reflected the distinction between four-year gymnasiums and three- or four-year vocational high schools (attended mostly by adolescents raised in families of lower socioeconomic status) well. Considering their proportion in the population of second grade highschool students $(30.1 \%)$, gymnasium students were slightly overrepresented in the sample $(34.3 \%)$.

Most adolescents were currently living with both parents $(78.0 \%)$. Over a half of participants reported that their mother and/or father had completed secondary education $(54.1 \%$ and $58.3 \%$, respectively). Of the rest, most had college-educated parents $(36.4 \%$ and $39.1 \%)$. Only $16.4 \%$ of participants stated that they planned to get a job after finishing high school; others intended to enroll in a college. A relative majority of participants attended religious services several times a year (36.1\%), followed by $21.6 \%$ of participants who attended them once to 
several times a month. Similar proportions of adolescents reported never going to church (15.7\%) and going to church on weekly basis or more often (15.4\%).

Only participants who reported SEM use in the past six months (1,265 adolescents, of whom $37 \%$ were women) were included in the analyses presented in this study.

\section{Procedure}

In April 2015, 69 of 90 high schools in the capital city (Zagreb) and the surrounding county were contacted for participation in an online panel study of the effects of sexualized media on young people's beliefs, attitudes, and behaviors. Small private schools, specialized art schools, and several smaller county schools were omitted. Schoolmasters in ten of the contacted schools refused to participate in the study. Over 7,350 leaflets were distributed to second-year students in the selected schools. Each contained information about the study (for students and their parents), a unique code, and instructions for online registration. Prospective participants were asked to visit the study web site and register using their e-mail address or Facebook account. In total, 2,655 students registered (a 36\% response rate). When logging in to participate in the study, each participant needed to type in his/her unique code printed on the leaflet they received in school. Each code number was unique and usable only once, making duplications unlikely.

Once registered, and after providing informed consent by clicking on the appropriate button, students were able to take an online survey. On average, the questionnaire, which included five sections (sociodemographic indicators; psychological characteristics; beliefs and attitudes; sexualized media use; and sexual behaviors), took 17 minutes to complete. The questionnaire application supported taking the survey using a smartphone. By completing the survey, participants were included in a lottery, in which 200 shopping mall vouchers, each worth 
about $\$ 7$ (or $6.5 €$ ), were awarded. All study procedures were approved by the Ethical Research Committee of the Faculty of Humanities and Social Sciences, University of Zagreb.

\section{Measures}

Three dependent variables were used in this study. Sexual experience was assessed by asking participants about different sexual experiences ranging from light petting to sexual intercourse. In total, five sexual activities were listed with a yes/no format for entering answers. Sexual activities experienced by the participant were summed into a composite ordinal indicator that showed high internal consistency (Guttman's $\lambda=0.88$ ). Sexual aggressiveness, defined in this study as having sexually coerced someone, was measured by a single-item indicator. The question: "Have you ever kissed, inappropriately touched or done something sexual to a person against her/his will?", was followed by three possible answers: "never", "once”, and "more than once". Finally, sexting was indicated by an additive scale composed of four items asking about the number of times in the past six months that the participant has sent a sexual message, sexy photograph of oneself, sexy video clip of oneself, or a pornographic photograph or video clip to someone. A five-point scale, ranging from $1=$ not once to $5=6$ or more times, was used to record responses. The composite indicator had acceptable internal consistency (Cronbach's $\alpha=$ 0.74); higher scores denote more frequent sexting. All three dependent variables were treated as manifest variables and were included in analyses as linear combinations (sexual experience and sexting) or a single-item indicator (sexual aggressiveness).

Four predictor variables were included in the study as latent constructs. Pornography or SEM was defined as any material which openly (i.e., not censored) depicts sexual activity. Material which shows naked bodies but not sexual intercourse or other sexual activity does not belong to pornography as here defined. Three items were used to assess SEM use: (a) frequency of SEM use in the past six months, (b) frequency of SEM use at the end of primary school (i.e., 
two years earlier), and (c) number of times SEM was accessed in the past week. The first two items had eight-point scales, ranging from $1=$ never to $8=$ several times a day, for anchoring answers. Answers to the final item ranged from 0 to 10 or more times. The three items were highly correlated $\left(r_{\mathrm{s}}=0.68-0.83, p<0.001\right.$; Cronbach's $\left.\alpha=0.85\right)$. Perceived pornography realism, the construct measuring the extent to which one believes that pornography realistically portrays sex, was assessed with four items (e.g., Sex depicted in pornography is very similar to sex in real life; One can learn a lot about sex by watching pornography) adapted from the fouritem scale developed by Peter and Valkenburg (2006). Response options ranged from $1=$ completely disagree to $5=$ completely agree, with higher scores denoting higher levels of perceived pornography realism. The scale had satisfactory reliability in this study (Cronbach's $\alpha$ $=0.86)$.

Sexual permissiveness in the context of adolescent sexuality was indicated by answers to four questions asking about personal acceptability of a 16-year-old having sex ("To what extent do you consider acceptable that a 16-year old has sex?") and multiple partners, as well as of sex on the first date and sex without emotional attachment ("To what extent do you consider acceptable to have sex without infatuation or love?"). Response options ranged from $1=$ completely disagree to $5=$ completely agree. The scale had acceptable internal consistency (Cronbach's $\alpha=0.78)$.

Parental monitoring was assessed by four items (e.g., My parents always know where I am; My parents know the friends I hang out with) previously validated in a national probabilitybased study of young adults (Landripet, Baćak, \& Štulhofer, 2010). The response options ranged from $1=$ does not apply to me at all to $5=$ applies to me completely. In this study, Cronbach's $\alpha$ for the scale was 0.81 .

\section{Analytical Strategy}


The analyses presented in this paper were conducted in two steps. In the first, preparatory, step (presented here) we aimed to produce group-equivalent measurement models to enable the testing of gender differences in final structural models (the second step). Taking into account well-documented gender differences in SEM use (Peter \& Valkenburg, 2016), as well as the empirical findings pointing that parental monitoring may have gender-specific role in the context of adolescent sexuality (Štulhofer, Graham, Božićević, Kufrin, \& Ajduković, 2009), it was necessary to consider possible gender-specific observations.

To ensure measurement invariance by gender, we carried out multi-group confirmatory factor analysis (CFA) for each latent dimension to be included in the model. Based on standard recommendations (Hu \& Bentler, 1999; Kline, 2011), several fit measures were used to assess gender differences $\left(\chi^{2}, \chi^{2} / d f\right.$, RMSEA, SRMR and CFI). For each latent variable, the baseline model (the model with freely estimated parameters) was compared with the metric and residual variance invariant model (the model in which factor loadings and residual variances were held equal in male and female groups). Since all four comparisons yielded significant chi-square differences, each freely estimated model was compared with a less restrictive model, in which only factor loadings were constrained across-groups. The metric invariance hypothesis held for the latent construct of parental monitoring $\left(\chi_{(4)}^{2}=7.06, p>.42 ; \chi^{2} / d f=1.77\right.$; RMSEA $=.004$; CFI =1.0; Satorra-Bentler Scaled Chi-Square Difference Test $\Delta \chi_{(3)}^{2}=0.23, p>.97$ ), but not for the three remaining latent factors (i.e. SEM use, pornography realism and sexual permissiveness). When measurement invariance cannot be satisfied, partial measurement invariance may be an alternative to explore (Byrne, Shavelson \& Muthen, 1989). Partial measurement invariance exists when some of the model parameters are held invariant across groups, while others are freely estimated. Less rigorous, this type of invariance is a compromise between full betweengroup model equivalence and the empirical reality which often deviates from desirable 
parsimonious solutions. Based on content analysis of the items, we started the procedure by freely estimating one item per factor and then testing chi-square differences against the baseline model. In the case of pornography realism, a residual covariance was added to the model (as suggested by its high modification index value) prior to the model comparison to obtain acceptable baseline model fit. Conceptually, this covariance made sense, as the two items (I find pornographic depiction of sex realistic and Pornographic portrayal of sex is very similar to sex in real life) substantially overlapped. Partial metric invariance for pornography realism was found with three across-group constrained loadings, one constrained residual covariance and two freely estimated loadings $\left(\chi_{(5)}^{2}=7.3, p>.20 ; \chi^{2} / d f=1.46 ; \mathrm{RMSEA}=.027 ; \mathrm{CFI}=.998 ; \Delta \chi_{(2)}^{2}=2.1, p>\right.$ $.35)$.

As in the case of pornography realism, modification indices for the sexual permissiveness baseline model suggested adding a residual covariance between two items that indicate the acceptance of casual sex (It is acceptable to have sex on the first date and It is acceptable to have sex without infatuation or love) to obtain adequate fit. Metric invariance held with three constrained loadings, one constrained residual covariance and two freely estimated factor loadings $\left(\chi_{(5)}^{2}=13.45, p<.02 ; \chi^{2} / d f=2.69 ; \mathrm{RMSEA}=.052 ; \mathrm{CFI}=.99 ; \Delta \chi_{(2)}^{2}=2.47 p>.29\right)$. Finally, the pornography use model demonstrated partial metric invariance with two constrained and two freely estimated factor loadings $\left(\chi_{(1)}^{2}=1.87, p>.17 ; \chi^{2} / d f=1.87\right.$; RMSEA $=.037$; CFI $=$ $\left..99 ; \Delta \chi_{(1)}^{2}=1.87, p>.17\right)$.

In the second step, partially invariant measurement models were used to build the three proposed structural equation models, with sexual activity, sexual aggressiveness and sexting as dependent variables (cf. Figure 1). Taking into account well-documented gender differences in SEM use and some of its outcomes (Peter \& Valkenburg, 2016; Short, Black, Smith, Wetterneck, \& Wells, 2012), the assessment of structural relationships among the constructs of interest was 
carried out by gender, in the form of multi-group testing. All statistical analyses were carried out using R (version 3.2.1) and the laavan package (version 0.5-18) for structural equation modeling (Rosseel, 2012). Because deviations from multivariate normality obtained with Mardia's test (Mardia, 1970) were significant among indicators of all four latent constructs, a robust maximum likelihood estimator (MLR) with robust (Huber-White) standard errors (Huber, 1967; White, 1982) was used to estimate parameters and model fit.

\section{RESULTS}

To address often reported differences in SEM use and parental control in male and female adolescents, we first analyzed gender differences in the key indicators. For convenience, all indicators were treated as manifest variables. Significant gender differences were observed in parental monitoring (Cohen's $d=.23, p<.001$ ), sexual permissiveness (Cohen's $d=.49, p<$ $.001)$, perceived SEM realism (Cohen's $d=.34, p<.001)$ and the frequency of SEM use (Cohen's $d=1.61, p<.001)$. Female participants reported a higher mean level of parental monitoring, while male participants reported higher sexual permissiveness, perceived SEM realism, and SEM use. As expected, only the difference in SEM use was large in size. No significant gender differences were found in any of the three outcomes (sexual experience, sexting, and sexual aggressiveness). In both genders, the behavioral outcomes were significantly interrelated, with an exception of the association between sexual experience and sexual aggressiveness among female participants, which bordered on significance $\left(r_{\mathrm{s}}=.09, p<.06\right)$. Among male adolescents, the associations between sexual aggressiveness and sexual experience and sexting were weak $\left(r_{\mathrm{S}}=.13\right.$ and $.21, p<.001$, respectively), unlike the sexual experience and sexting one $\left(r_{\mathrm{S}}=.48, p<.001\right)$. Similar relationships were observed among female adolescents. The association between sexting and sexual aggressiveness was weak $\left(r_{\mathrm{S}}=.16, p<.001\right)$ and the correlation between sexual experience and sexting moderately strong $\left(r_{\mathrm{S}}=.50, p<.001\right)$. 
Considering that this paper's analytical focus was on structural associations, gender invariance of the three latent covariances among the exogenous variables was explored first. Both the model with freely estimated covariances and the one characterized by constrained (across gender) covariances resulted in acceptable fit $\left(\chi_{(87)}^{2}=211.38, \chi^{2} / d f=2.43, \mathrm{CFI}=.97, \mathrm{RMSEA}=\right.$ .048 , and $\chi_{(90)}^{2}=219.26, \chi^{2} / d f=2.44, \mathrm{CFI}=.97, \mathrm{RMSEA}=.048$, respectively). Following chisquare comparison, which pointed to a slightly better fit of the model with freely estimated covariances $\left(\Delta \chi_{(3)}^{2}=7.87, p<.05\right)$, latent covariances were treated as gender specific in all subsequent analyses.

\section{Sexual Experience Model}

An acceptable fit characterized the baseline multi-group model of sexual experience (Figure 2), which consisted of the partially invariant measurement part and freely estimated regression paths: $\chi^{2}{ }_{(200)}=491, p<.001 ; \chi^{2} / d f=2.46 ; \mathrm{RMSEA}=.048 ; \mathrm{CFI}=.95$. According to Satorra-Bentler test results, the model's fit was not significantly different $\left(\Delta \chi_{(5)}^{2}=7.08, p>.22\right)$ from the fit of a nested model, in which regression paths were constrained to be equal for male and female participants $\left(\chi_{(205)}^{2}=498.08, p<.001 ; \chi^{2} / d f=2.43 ; \mathrm{RMSEA}=.048 ; \mathrm{CFI}=.95\right)$. Structural associations were, thus, treated as gender non-specific.

Earlier sexual experience was significantly associated with parental monitoring $(b=-0.29$, $p<.001)$, sexual permissiveness $(b=0.74, p<.001)$, pornography realism $(b=0.18, p<.05)$, and the frequency of SEM use $(b=0.11, p<.05)$. Lower parental monitoring, higher sexual permissiveness, higher perceived reality of pornographic content, and more frequent SEM use were predictive of a higher likelihood of participants' sexual experience. As hypothesized, SEM use also had a significant indirect effect $(b=0.02, p<.05)$ on the outcome through perceived pornography realism. The model explained about a tenth of a variance in male and female adolescents' earlier sexual experience (9.6\% and $8 \%$, respectively). 


\section{Sexual Aggressiveness Model}

Both the baseline $\left(\chi_{(200)}^{2}=396.48, p<.001 ; \chi^{2} / d f=1.98 ; \mathrm{RMSEA}=.039 ; \mathrm{CFI}=.97\right)$ and a gender-invariant nested model $\left(\chi_{(205)}^{2}=405.28, p<.001 ; \chi^{2} / d f=1.98 ; \mathrm{RMSEA}=.039 ; \mathrm{CFI}=.97\right)$ of adolescent sexual aggressiveness showed acceptable fit to data. Non-significant SattoraBentler test results pointed to gender non-specificity of the structural part of the model $\left(\Delta \chi^{2}{ }_{(5)}=\right.$ 8.97, $p>.11$ ). The hypothesized association, either direct or indirect (through perceived pornography realism), between SEM use and adolescent sexual aggressiveness was nonsignificant in this sample. Sexual aggressiveness was negatively associated with parental monitoring $(b=-0.06, p<.01)$, but positively related to participants' sexual permissiveness $(b=$ $0.08, p<.05$ ). The model explained less than $5 \%$ of variance in sexual aggressiveness (Figure 3 ).

\section{Sexting Model}

The baseline model with sexting as the dependent variable was also characterized by a satisfactory fit $\left(\chi_{(200)}^{2}=439.45, p<.001 ; \chi^{2} / d f=2.20 ; \mathrm{RMSEA}=.044 ; \mathrm{CFI}=.96\right)$. As in the previous cases, the fit of a nested model $\left(\chi_{(205)}^{2}=450.44, p<.001 ; \chi^{2} / d f=2.20 ;\right.$ RMSEA $=.044$; $\mathrm{CFI}=.96)$ with structural parts of the model constrained did not differ significantly from the baseline model's fit $\left(\Delta \chi_{(5)}^{2}=10.98, p>.05\right)$, pointing to the model's gender-invariance. While parental monitoring significantly decreased the likelihood of sexting $(b=-0.73, p<.001)$, sexual permissiveness $(b=1.50, p<.001)$, pornography realism $(b=0.50, p<.001)$, and SEM use $(b=$ $0.62, p<.001$ ) increased it (Figure 4). Perceived pornography realism partially mediated the association between SEM use and sexting $(b=0.05, p<.01)$. Overall, the model explained $17.6 \%$ and $14.5 \%$ of variance in sexting among male and female adolescents, respectively.

\section{Buffering Role of Parental Monitoring?}

In all three structural models presented above, parental monitoring was significantly and negatively associated with both the frequency of SEM use and the three outcomes. To further 
explore the role of parental monitoring - particularly the question of whether it moderated the association between SEM use and sexual experience and sexting - additional multivariate OLS regression analyses were carried out separately for female and male adolescents (results not presented here). All four regression models included three independent variables: composite indicator of parental monitoring, frequency of SEM use (transformed into a manifest variable represented by factor scores), and parental monitoring $\mathrm{x}$ frequency of SEM use interaction term. None of the regression analyses pointed to a statistically significant moderating effect of parental monitoring.

\section{DISCUSSION}

Using a large-scale online sample of Croatian adolescents, we explored the role of parental monitoring in adolescent vulnerability to SEM-associated risky or potentially adverse outcomes. Informed by the DSMM (Valkenburg \& Peter, 2013), structural modeling of three behavioral outcomes — sexual experience, sexting, and sexual aggressiveness — enabled an assessment of the contribution of parental monitoring relative to SEM use, perceived SEM realism, and the participant's sexual permissiveness. Among both female and male adolescents, parental monitoring was consistently and negatively related to the problematic or potentially risky sexual outcomes. In addition, higher levels of parental monitoring were associated with a lower acceptance of sexual permissiveness and a lower frequency of SEM use. Taken together, the findings confirm the importance of dispositional (sexual permissiveness) and social aspects (parental monitoring) of adolescent susceptibility to media effects, as well as the mediating role of cognitive response states (perceived pornography realism). The observed similarity of structural associations among the key constructs in male and female adolescents points to the need of moving beyond the oft-reported differences in mean levels of media exposure to explore commonalities in the process of media-affected sexual socialization — as recently demonstrated in 
several studies (Baams et al., 2015; Van Ouytsel, Ponnet, \& Walrave, 2014; Vandenbosch \& Eggermont, 2013).

Partially corroborating initial expectations, SEM use was significantly associated with sexual experience and sexting, but not with sexual aggressiveness. According to the conceptually directed pathways, the association between SEM use and adolescents' sexual experience and sexting was partially mediated by perceived pornography realism. Interestingly, the findings pointed to the gender non-specific structure of the associations studied, despite gender differences in levels of SEM use, perceived pornography realism and parental monitoring. The findings that the pathways from SEM use to the outcomes and those linking parental monitoring with the outcomes were similar for female and male participants suggest that differential exposure to sexualized media may not easily translate into different outcomes, but also that gender-specific levels of parental monitoring may not differ in their protective potential.

In this study, parental monitoring was systematically related to the behavioral outcomes, as well as to the reported SEM use and the acceptance of sexually permissive attitudes (the two have been repeatedly shown to correlate; Baams et al., 2015; Lo \& Wei, 2005; Wright, 2013). However, the hypothesized moderating effect of parental monitoring on the association between SEM use and the behavioral outcomes was not empirically supported. In that respect, parental efforts to monitor their adolescent's whereabouts, activities and contacts appear to reduce both exposure and vulnerability to (possible) media effects. Underlying mechanisms are likely multifaceted and both distal (indirect) and proximal (direct), ranging from inoculating one's children with values that may protect them from adverse outcomes to regulating their contacts (i.e., encouraging the company of some but not other peers).

In the context of contemporary concerns over adverse effects of SEM use among young people (Horvath et al., 2013; Petley, 2015), our analyses pointed to significant but small-sized 
associations between SEM use and sexual experience and sexting. Both relationships have been reported, but the evidence is scarce (Vandenbosch \& Eggermont, 2013; Van Ouytsel, Ponnet, \& Walrave, 2014). Little is known whether SEM use is not only associated with earlier but also riskier sexual debut or if cognitive and emotional evaluation of pornography moderates its relationship with the practice of sexting. Given the prevalence of SEM and sexting among young people, the growing body of research on sexting should include the assessment of participants' SEM use, attitudes toward SEM, and personal evaluation of SEM content. Such an approach would also enable a more nuanced and evidence-based approach to the media sexualization of youth hypothesis.

The conceptually assumed influence of SEM use on sexual initiation and sexting was partly mediated by the assessment of pornography realism. Corroborating the findings from a couple of Dutch studies (Baams et al., 2015; Peter \& Valkenburg, 2010), the significant effects of perceived SEM realism point to the importance of young people's interpretations of media content. Making sense of the media they use is essential for adolescents' identity (Steele, 1999). Perceiving SEM as realistic_- particularly if one believes that the perception is shared by his or her peers - may increase the likelihood of accepting SEM-promoted sexual scripts and lead to their reenactment (cf. Wright, 2011; Baams et al., 2015). Although the belief that SEM can realistically depict human sexuality does not easily translate into using it as a central source of information about sexuality (Löfgren-Mårteson \& Månsson, 2010; Matthiesen, 2013), the fact that pornography realism was positively associated with the frequency of SEM use corroborates the importance of media response states in understanding adolescent media use and its effects (Steele, 1999; Valkenburg \& Peter, 2013). Surprisingly, given that SEM is mostly tailored to a male audience, the mediating effects of SEM realism did not differ across gender. 
Taking into account a long tradition of research into possible links between SEM use and sexual aggression and violence (Hald et al., 2014), it should be noted that in this sample of Croatian adolescents no significant relationship was found between sexual aggressiveness and either SEM use or perceived SEM realism. The finding should be balanced against our broad operational definition of sexual aggression, but also contextualized within the confluence model of sexual aggression (Malamuth \& Huppin, 2005). Considering that the model stresses the qualifying roles of specific (violent) SEM contents and particular personality characteristics (hostile masculinity), our findings most likely reflect a lack of association between mainstream SEM use and sexual aggressiveness in most of the sampled adolescents. Although it should be acknowledged that the structural model explained a marginal percentage of variance in sexual aggressiveness, the link between sexual permissiveness and self-reported sexually aggressive behavior is intriguing. Hypothetically, several analytical mechanisms may underlie the observed relationship, from a higher likelihood of making false assumptions about peers' sexual interest to a less clear understanding of sexual agency and consent among more permissive young people. More research is needed to explore potentially harmful aspects of teenage sexual permissiveness. In practical terms, this study's findings reiterate the importance of media literacy programs, which aim to equip young people with a more critical perspective on overt and covert mass media messages, as well as to help them distinguish the reality from media constructions of reality. Given that exposure to SEM often precedes first sexual experiences, this may be especially relevant for SEM users and their sexual socialization (Štulhofer, Buško, \& Landripet, 2010). In the absence of media literacy programs in Croatian schools, the recent initiative by the Croatian Agency for Electronic Media, which resulted in a website devoted to the promotion of the concept of media literacy among parents and educators (http://www.medijskapismenost.hr/), is noteworthy. Although our study was not designed to provide insights about psychosocial 
mechanisms underlying the association between parental monitoring and the adverse or potentially risky outcomes among 16-year-olds, the observed protective role of this specific kind of parental engagement is highly pertinent. Parents need to be encouraged in taking sustained interest in their adolescent child's activities, as well as systematically supported in confronting their fears about the contemporary digital landscape working against effective parenting.

Overall, our findings need to be weighed against several study limitations. First, the nonprobabilistic sampling, coupled with a low participation rate, precludes any conclusions related to the prevalence of either pornography use or the selected outcomes among Croatian adolescents. However, the size and heterogeneity of our sample are strengths in a more analytical context, such as the exploration of structural ties among the constructs of interest that were presented here. Second, unlike independent variables, the three dependent variables were treated as manifest (observed) variables in the structural models, as if they perfectly measured their respective constructs. Moreover, one of the three behavioral outcomes (sexual aggressiveness) was measured by a single-item indicator characterized by high face validity but unknown psychometric properties. Third, the latent measures in this study were found only partially, not fully, gender invariant. Methodologically, this is often understood to negatively affect the robustness of multi-group analyses. Following the literature on socially-generated gender differences in young people's sexuality (Boislard, van de Bongardt, \& Blais, 2016; Buckingham \& Bragg, 2004; Matthiesen, 2013), we consider the limitation related to partial invariance of latent constructs hardly avoidable and, thus, tolerable.

Finally, the cross-sectional character of this study makes causal interpretation impossible. The reader should be warned against assuming that pornography use causes sexual activity or sexting in this sample of adolescents, as we cannot rule out the opposite direction of influence or bi-directional effects. A similar caution applies to the association between parental monitoring 
and the three outcomes. Although, for example, higher levels of parental monitoring may decrease the likelihood of sexual aggressiveness (for example, by restricting the adolescent's access to alcohol), the opposite causal relationship —in which the adolescent's tendency toward sexual aggressiveness results in lower parental monitoring (either due to rebelling against it or because the parents are systematically fed with elaborate lies and deceptions)—is also plausible. Future research should further explore the role of parental monitoring, particularly by testing possible moderating effects of parenting styles on the association between monitoring and the behavioral outcomes. In countries high in religiosity, such as Croatia, interaction between religiosity and parental monitoring should also be addressed, not least because religiosity may not always be a protective factor in the context of adolescent sexuality (Zaleski \& Schiaffino, 2000). In regard to the role of parenting practices in the prevention of adolescent risk taking (DeVore \& Ginsburg, 2005; DiClemente, et al., 2001), more insights are needed about the components of parenting styles that make monitoring more efficient, less efficient, or even counterproductive (cf. Van de Bongardt, Reitz, \& Deković, 2016).

\section{CONCLUSIONS}

It has been argued that new digital technologies make parental monitoring of the media content that their children are consuming increasingly difficult (Clark, 2014). Not surprisingly, some parents seem to believe that their oversight of their adolescent children's interests and behaviors is diminishing, notwithstanding the efforts to maintain the desired level of parental monitoring. This concern seems to be at least partly fueled by the realization that young people have more expertise in new communication technologies than their parents and educators. In this context, our findings are encouraging. Parental monitoring was shown to be systematically and significantly associated with all three risky or potentially detrimental behavioral outcomes addressed in this study, suggesting its protective role. Considering that the relationships between 
parental monitoring and the outcomes were more consistent than the relationships between adolescent SEM use and the outcomes, parental engagement remains important in the Internet era.

\section{Acknowledgement:}

This work has been fully funded by Croatian Science Foundation (grant number 9221). 


\section{REFERENCES}

Baams, L., Overbeek, H. Dubas, J. S., Doornwaard, S. M., Rommes, E., \& van Aken, M. A. G. (2015). Perceived realism moderates the relation between sexualized media consumption and permissive sexual attitudes in Dutch adolescents. Archives of Sexual Behavior, 44, 743-754.

Benotsch, E. G., Snipes, D. J., Martin, A. M., \& Bull, S. S. (2013). Sexting, substance use, and sexual risk behavior in young adults. Journal of Adolescent Health, 52, 307-313.

Boislard, M. A., van de Bongardt, D., \& Blais, M. (2016). Sexuality (and lack thereof) in adolescence and early adulthood: A review of the literature. Behavioral Sciences, 6, doi:10.3390/bs6010008.

Bonino, S., Ciairano, S., Rabaglietti, E., \& Cattelino, E. (2006). Use of pornography and selfreported engagement in sexual violence among adolescents. European Journal of Developmental Psychology, 3, 265-288.

Borawski, E. A., Ievers-Landis, C. E., Lovegreen, L. D., \& Trapl, E. S. (2003). Parental monitoring, negotiated unsupervised time, and parental trust: The role of perceived parenting practices in adolescent health risk behaviors. Journal of Adolescent Health, 33, 60-70.

Boulat, M., Caddaye, D., D’Souza, H., Glyde, M., Hatwal, A., \& Jansz, C. (2013). Submission to the Victorian Parliament Law Reform Committee's inquiry into sexting. Retrieved 2 March 2016 from

http://www.parliament.vic.gov.au/file_uploads/LRC_Sexting_Final_Report_0c0rvqP5.pdf.

Brown, J. D., \& L'Engle, K. L. (2009). X-Rated: Sexual attitudes and behaviors associated with U.S. early adolescent's exposure to sexually explicit media. Communication Research, 36, 129-151. 
Brown, J. D., L’Engle, K. L., Pardun, C. J., Guo, G., Kenneavy, K., \& Jackson, C. (2006). Sexy media matter: Exposure to sexual content in music, movies, television, and magazines predicts black and white adolescent's sexual behavior. Pediatrics, 117, 1018-1027.

Buckingham, D., \& Bragg, S. (2004). Young people, sex and the media: The facts of life? New York: Palgrave MacMillan.

Byrne, B. M., Shavelson, R. J., \& Muthén, B. (1989). Testing for the equivalence of factor covariance and mean structures: The issue of partial measurement invariance. Psychological Bulletin, 105, 456-466.

Carrol, J. S., Padilla-Walker, L., Nelson, L. J., Olson, C. D., Barry, C. M., \& Madsen, S. D. (2008). Generation XXX: Pornography acceptance and use among emerging adults. Journal of Adolescent Research, 23, 6-30.

Clark, A. B. (2014). Parenting through the digital revolution. In: Saleh, F., Grudzinskas, A., \& Judge, A. (Eds.) Adolescent sexual behavior in the digital age: Consideration for clinicians, legal professionals and educators. Oxford: Oxford University Press, pp. 247-261.

Collins, R., Elliot, M., Berry, S., Kanouse, D., Kunkel, D., Hunter, S., \& Miu, A. (2004). Watching sex on television predicts adolescent initiation of sexual behavior. Pediatrics, 114 , 280-289.

Dake, J. A., Price, D.H., Mazriaz, L. \& Ward, B. (2012). Prevalence and correlates of sexting behavior in adolescents. American Journal of Sexuality Education, 7, 1-15.

de Graaf, H., van de Schoot, R., Woertman, L., Hawk, S. T., \& Meeus, W. (2012). Family cohesion and romantic and sexual initiation: A three wave longitudinal study. Journal of Youth and Adolescence, 41, 583-592. 
Deptula, D. P., Henry, D. B., \& Schoeny, M. E. (2010). How can parents make a difference? Longitudinal associations with adolescent sexual behavior. Journal of Family Psychology, $24,731-739$.

DeVore, E. R., \& Ginsburg, K. R. (2005). The protective effects of good parenting on adolescents. Current Opinion in Pediatrics, 17, 460-465.

DiClemente, R. J., Wingood, G. M., Crosby, R., Sionean, C., Cobb, B. K., Harrington, K.,... Oh, M. K. (2001). Parental monitoring: Association with adolescents' risk behaviors. Pediatrics, $107,1363-1368$.

East, P. L., Khoo, S. T., \& Reyes, B. T. (2006). Risk and protective factors predictive of adolescent pregnancy: A longitudinal, prospective study. Applied Developmental Science, 10, 188-199.

Ferguson, C. J. (2011). Sexting behaviours among young Hispanic women: Incidence and association with other high-risk sexual behaviors. Psychiatric Quarterly, 82, 239-243.

Hald, G. M., Kuyper, L., Adam, P. C. G., de Wit, J. B. F. (2013). Does viewing explain doing? Assessing the association between sexually explicit materials use and sexual behaviors in a large sample of Dutch adolescents and young adults. Journal of Sexual Medicine, 10, 29862995.

Hald, G. M., Seaman, C., \& Linz, D. (2014). Sexuality and pornography. In D. Tolman, L. Diamond (Eds.), APA handbook of sexuality and psychology: Vol. 2. Contextual approaches (pp. 3-35). Washington, DC: American Psychological Association.

Horvath, M. A. H., Alys, L., \& Massey, K. (2013). 'Basically... porn is everywhere' A rapid evidence assessment of the effects that access and exposure to pornography has on children and young people. London: Office of the Children's Commissioner. Retrieved 2 April 2016 from: 
http://www.childrenscommissioner.gov.uk/sites/default/files/publications/Basically_porn_is_ everywhere.pdf.

Hu, L., \& Bentler, P. M. (1999). Cutoff criteria for fit indexes in covariance structure analysis: Conventional criteria versus new alternatives. Structural Equation Modeling, 6, 1-55. doi: 10.1080/10705519909540118.

Huber, P. J. (1967). The behavior of maximum likelihood estimates under nonstandard conditions, In Proc. Fifth Berkeley Symposium on Mathematical Statistics and Probability, 1, 221-233. University of California Press, Berkeley.

Klettke, B., Hallford, D. J., \& Mellor, D. J. (2014). Sexting prevalence and correlates: A systematic literature review. Clinical Psychology Review, 34, 44-53.

Kline, R. B. (2011). Principles and practice of structural equation modeling. New York: Guilford.

Kraus, S. W. \& Russell, B. (2008). Early sexual experiences: The role of internet access and sexually explicit material. Cyber Psychology \& Behavior, 11, 162-168.

Landripet, I., Baćak, V., \& Štulhofer, A. (2011). Changes in HIV and STI related sexual risk taking among young Croatian adults: Findings from the 2005 and 2010 population-based surveys. Croatian Medical Journal, 52, 458-468.

Lo, V. H., \& Wei, R. (2005) Exposure to Internet pornography and Taiwanese adolescents' sexual attitudes and behavior. Journal of Broadcasting \& Electronic Media, 49, 221-237.

Löfgren-Mårteson, L., \& Månsson, S. A. (2010). Lust, love, and life: A qualitative study of Swedish adolescents' perceptions and experiences with pornography. Journal of Sex Research, 47, 568-579. 
Luder, M. T., Pittet, I., Beerchtold, A., Akre, C., Michaud, P. A., \& Suris, J. C. (2011).

Associations between online pornography and sexual behavior among adolescents: Myth or reality? Archives of Sexual Behavior, 40, 1027-1035.

Malamuth, N., \& Huppin, M. (2005). Pornography and teenagers: The importance of individual differences. Adolescent Medicine, 16, 315-326.

Mardia, K. V. (1970). Measures of multivariate skewness and kurtosis with applications. Biometrika, 57, 519-530.

Matthiesen, S. (2013). Youth sexuality in the Internet age: A qualitative study of the social and sexual relationships of young people. Cologne: Bundeszentrale für gesundheitliche Afklärung.

Mattebo, M., Tyden, T., Haggstrom-Nordin, E., \& Nilsson, K. W. (2013). Pornography consumption, sexual experiences, lifestyles, and self-rated health among male adolescents in Sweden. Journal of Developmental and Behavioral Pediatrics, 34, 460-468.

McNair, B. (2002). Striptease culture: Sex, media and the democratization of desire. London: Routledge.

Mitchell, K. J., Finkerhor, D., Jones, L. M., \& Wolak, J. (2012). Prevalence and characteristics of youth sexting: A national study. Pediatrics, 129, 13-20.

Nikken, P., \& de Graaf, H. (2013). Reciprocal relationships between friends' and parental mediation of adolescents' media use and their sexual attitudes and behavior. Journal of Youth and Adolescence, 42, 1696-1707.

Owens, E. W., Behun, R. J., Manning, J. C., \& Reid, R. C. (2012). The impact of Internet pornography on adolescents: A review of the research. Sexual addiction \& Compulsivity, 19, 99-122. 
Pardun, C., L’Engle, K. L., \& Brown, J. (2005). Linking exposure to outcomes: Early adolescents' consumption of sexual content in six media. Mass Communication \& Society, 8 , 75-91.

Peter, J., \& Valkenburg, P. M. (2006). Adolescents' exposure to sexually explicit online material and recreational attitudes toward sex. Journal of Communication, 56, 639-660. doi:10.1111/j.1460-2466.2006.00313.x.

Peter, J., \& Valkenburg, P. M. (2010). Processes underlying the effects of adolescents' use of sexually explicit Internet material: The role of perceived realism. Communication Research, $37,375-399$.

Peter, J., \& Valkenburg, P. M. (2011). The influence of sexually explicit internet material on sexual risk behavior: A comparison of adolescents and adults. Journal of Health Communication: International Perspectives, 16, 750-765.

Peter, J., \& Valkenburg, P. M. (2016). Adolescents and pornography: a review of 20 years of research. The Journal of Sex Research, 53, 1-23. doi: 10.1080/00224499.2016.1143441.

Peterson, J. L., Moore, K. A., \& Furstenberg, F. F. (1991). Television viewing and early initiation of sexual intercourse: Is there a link? Journal of Homosexuality, 21, 93-118.

Petley, J. (2015). The regulation of pornography on video-on-demand in the United Kingdom. Porn Studies, 1, 260-284.

Rice, E., Rhoades, H., Winetrobe, H., Sanchez, M., Montoya, J., Plant, A., \& Kordic, T. (2012). Sexually explicit cell phone messaging associated with sexual risk among adolescents. Pediatrics, 130, 667-673.

Ringrose, J., Gill, R., Livingstone, S., \& Harvey, L. (2012). A qualitative study of children, young people and "sexting": A report prepared for the NSPCC. London: NSPCC. Retrieved 
29 February 2016 from http://www.lse.ac.uk/media@1se/documents/MPP/Sexting-ReportNSPCC.pdf.

Rosseel, Y. (2012). lavaan: An R Package for Structural Equation Modeling. Journal of Statistical Software, 48, 1-36.

Scull, T. M., Malik, C. V., \& Kupersmidt, J. B. (2014). A media literacy education approach to teaching adolescents comprehensive sexual health education. Journal of Media Literacy Education, 6, 1-14.

Short, M. B., Black, L., Smith, A. H., Wetterneck, C. T., \& Wells, D. E. (2012). A review of Internet pornography use research: Methodology and content from the past 10 years. Cyberpsychology, Behavior, and Social Networking, 15, 13-23.

Sieverding, J. A., Adler, N., Witt, S., \& Ellen, J. (2005). The influence of parental monitoring on adolescent sexual initiation. Archives of Pediatrics and Adolescent Medicine, 159, 724-729.

Sinković, M., Štulhofer, A., \& Božić, J. (2013). Revisiting the association between pornography use and risky sexual behaviors: The role of early exposure to pornography and sexual sensation seeking. Journal of Sex Research, 50, 633-641.

Steele, J. R. (1999). Teenage sexuality and media practice: Factoring in the influences of family, friends, and school. Journal of Sex Research, 36, 331-341.

Sun, C., Bridges, A., Johnson, J. A., \& Ezzell, M. B. (2016). Pornography and the male sexual script: An analysis of consumption and sexual relations. Archives of Sexual Behavior, 45, 983-984.

Štulhofer, A., Graham, C., Božičević, I., Kufrin, K., \& Ajduković, D. (2009). An assessment of HIV/STI vulnerability and related sexual risk-taking in a nationally representative sample of young Croatian Adults, Archives of Sexual Behavior, 38, 209-225. 
Štulhofer, A., Buško, V., \& Landripet, I. (2010). Pornography, sexual socialization, and satisfaction among young men. Archives of Sexual Behavior, 39, 168-178.

Temple, J. R., Le, V. D., van den Berg, P., Ling, Y., Paul, J. A., \& Temple, B. W. (2014). Brief report: Teen sexting and psychosocial health. Journal of Adolescence, 37, 33-36.

Temple, J. R., \& Choi, H. (2014). Longitudinal association between teen sexting and sexual behavior. Pediatrics, 134, DOI: 10.1542/peds.2014-1974.

Valkenburg, P. M., \& Peter, J. (2013). The differential susceptibility to media effects model. Journal of Communication, 63, 221-243. doi:10.1111/jcom.12024.

Vandenbosch, L., \& Eggermont, S. (2013). Sexually explicit websites and sexual initiation: Reciprocal relationship and the moderating role of pubertal status. Journal of Research on Adolescence, 23, 621-634.

Van de Bongardt, D., de Graaf, H., Reitz, E., \& Deković, M. (2014). Parents as moderators of longitudinal associations between sexual peer norms and Dutch adolescent's sexual initiation and intention. Journal of Adolescent Health, 55, 388-393.

Van de Bongardt, D., Reitz, E., \& Deković, M. (2016). Indirect over-time relations between parenting and adolescents' sexual behaviors and emotions through global self-esteem. Journal of Sex Research, 53, 273-285.

Van Ouytsel, J., Ponnet, K., \& Walrave, M. (2014). The associations between adolescents' consumption of pornography and music videos and their sexting behavior. Cyberpsychology, Behavior, and Social Networking, 17, 772-778. doi: 10.1089/cyber.2014.0365.

Van Ouytsel, J., Walrave, M., \& Van Gool, E. (2014). Sexting: Between thrill and fear-how schools can respond. The Clearing House: A Journal of Educational Strategies, Issues and Ideas, 87, 204-212. 
Walrave, M., Heirman, W., \& Hallam, L. (2014). Under pressure to sext? Applying the theory of planned behaviour to adolescent sexting. Behaviour and Information Technology, 33, 86-98.

Wang, B., Stanton, B., Deveaux, L., Li, Y., \& Lunn, S. (2015). Dynamic relationships between parental monitoring, peer risk involvement and sexual risk behavior among Bahamian midadolescents. International Perspectives on Sexual and Reproductive Health, 41, 89-98.

Whitaker, D. J., \& Miller, K. S. (2000). Parent-adolescent discussions about sex and condoms impact on peer influences of sexual risk behavior. Journal of Adolescent Research, 15, 251273.

White, H. (1982). Maximum likelihood estimation of misspecified models. Econometrica, 50, $1-25$.

Wight, D., Williamson, L., \& Henderson, M. (2006). Parental influences on young people's sexual behavior: A longitudinal analysis. Journal of Adolescence, 29, 473-494.

Wright, P. J. (2011). Mass media effects on youth sexual behavior: Assessing the claim for causality. Communication Yearbook, 35, 343-386.

Wright, P. J. (2013). U.S. males and pornography, 1973-2010: Consumption, predictors, correlates. Journal of Sex Research, 50, 60-71.

Wright, P. J., \& Donnerstein, E. (2014). Sex Online: Pornography, Sexual Solicitation, and Sexting. Adolescent Medicine: State of the Art Reviews, 25, 574-589.

Wright, P. J., Tokunaga, R. S., \& Kraus, A. (2015). A meta-analysis of pornography consumption and actual acts of sexual aggression in general population studies. Journal of Communication, 66, 183-205. doi: 10.1111/jcom.12201.

Ybarra, M. L., Mitchell, K. J., Hamburger, M., Diener-West, M., \& Leaf, P. J. (2011). X-rated material and perpetration of sexually aggressive behavior among children and adolescents: is there a link? Aggressive Behavior, 37, 1-18. doi: 10.1002/ab.20367. 